\title{
An Investigation of baffle angles on Shell and Tube heat exchanger
}

\author{
Ragunath $\mathrm{L}^{1 \#}$, Mohanraj $\mathrm{C}^{2 *}$,Suriyakumar $\mathrm{S}^{3}$, Sasi Kumar $\mathrm{S}^{4}$, Balamurugan $\mathrm{C}^{5}$ \\ I\#, 2*Assistant Professor,Department of Mechanical, M.Kumarasamy college of engineering. \\ ${ }^{3,4,5}$ UG Students, Department of Mechanical \& M.Kumarasamy college of engineering. \\ Thalavapalayam, Karur, Tamil Nadu, India
}

\begin{abstract}
The turn of events and execution enhancement of shell and tube heat exchanger is an issue of incredible test and part of arising early innovation. The exhibition enhancement would serve an extraordinary commitment to assuage the swelled working expenses just as energy emergency. This paper grandstands every one of the experimental outcomes got from the constant framework investigation in different working conditions. Further it addresses examination for a few shell-and-tube heat exchangers with segmental confounds with various point parametric variety. The framework distinguishing proof has been done utilizing CFD investigation. The consolidated outcomes as for same shell-side stream rate show that, the heat move coproficient of the heat exchanger with astounds is higher than that of the heat exchanger without perplexes, while the shell-side pressing factor drop of the previous is even a lot of lower than that of the last mentioned. Further upgrade methods ought to be consolidated to improve shell-side heat move dependent on a similar stream rate. The near investigation of heat move coefficient per unit pressure drop shows that the Segmental Baffle Heat exchanger have critical execution advantage over Segmental Baffle Heat exchanger for similar mathematical arrangements.
\end{abstract}

Keywords - Heat exchanger, Helical baffles, Angles.

\section{INTRODUCTION}

Heat exchanger is a gadget that moving heat starting with one medium then onto the next. There is a wide assortment of Heat exchanger accessible for various applications. Boilers and condensers are remembered for the huge modern Heat exchanger in nuclear energy stations. The radiators and oil cooers are the type of heat exchangers in the vehicles. These Heat exchanger are more plentiful in all interaction businesses and synthetic ventures. This can be characterized in to various kinds dependent on not many essential idea.

A Shell and Tube heat exchanger is a class of Heat exchanger plans. It is the most well-known type of Heat exchanger utilized In petroleum treatment facilities and other enormous compound cycles, I $t$ appropriate for high pressing factor applications. As its name suggests this kind of Heat exchanger comprise of shell with a heap of cylinder inside it One liquid goes through the cylinder and anther liquid streams over the cylinder to move heat between the liquids. The arrangement of cylinders is known as a cylinder group. Aside from cylinder and shell confounds are significant parts in plan of shell and cylinder heat exchanger

\section{Materials AND Methods}

\begin{tabular}{|l|l|l|}
\hline Fluid medium used & Solid material used & Boundary conditions \\
\hline Water & Copper & $\begin{array}{l}\text { Inlet Type: Velocity inlet }(0.5 \mathrm{~m} / \mathrm{s}) \\
\text { Temperature of cold fluid }(300 \mathrm{k}) \\
\text { Temperature of hot fluid }(373 \mathrm{k}) \\
\text { Outlet Type: Pressure outlet } \\
\text { No of iterations used: } 100\end{array}$ \\
& & \\
& & \\
\hline
\end{tabular}




\section{III.EXPERIMENTAL WORK}

\subsection{Solid works Designs}

\begin{tabular}{|c|c|c|}
\hline Design of $0^{\circ}$ baffles & Design of $15^{\circ}$ baffles & Design of $25^{\circ}$ baffles \\
\hline & & \\
\hline
\end{tabular}

\subsection{Ansys Design}

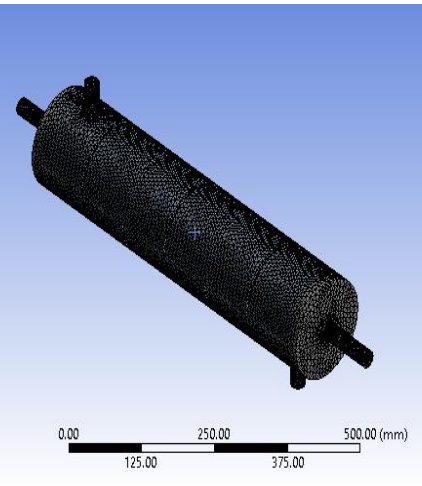

Fig 4

Meshed view

\subsection{Results of $0^{\circ}$ baffle plates}

\section{RESULT AND DISCUSSION}

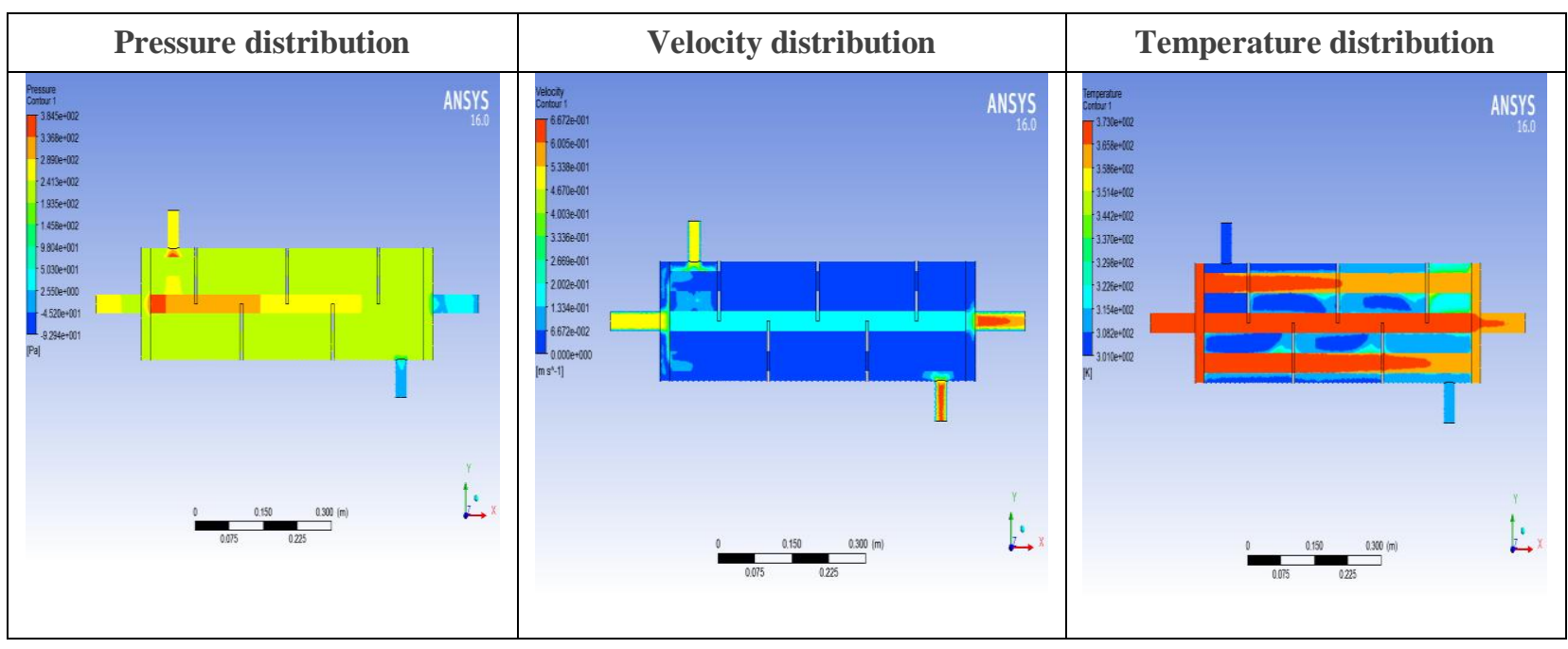




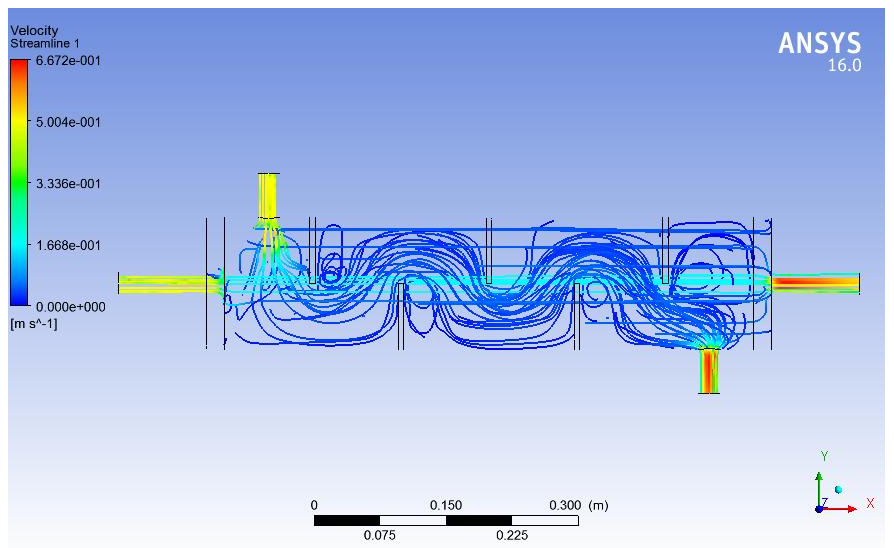

Flow patterns on $0^{\circ}$ baffle plates

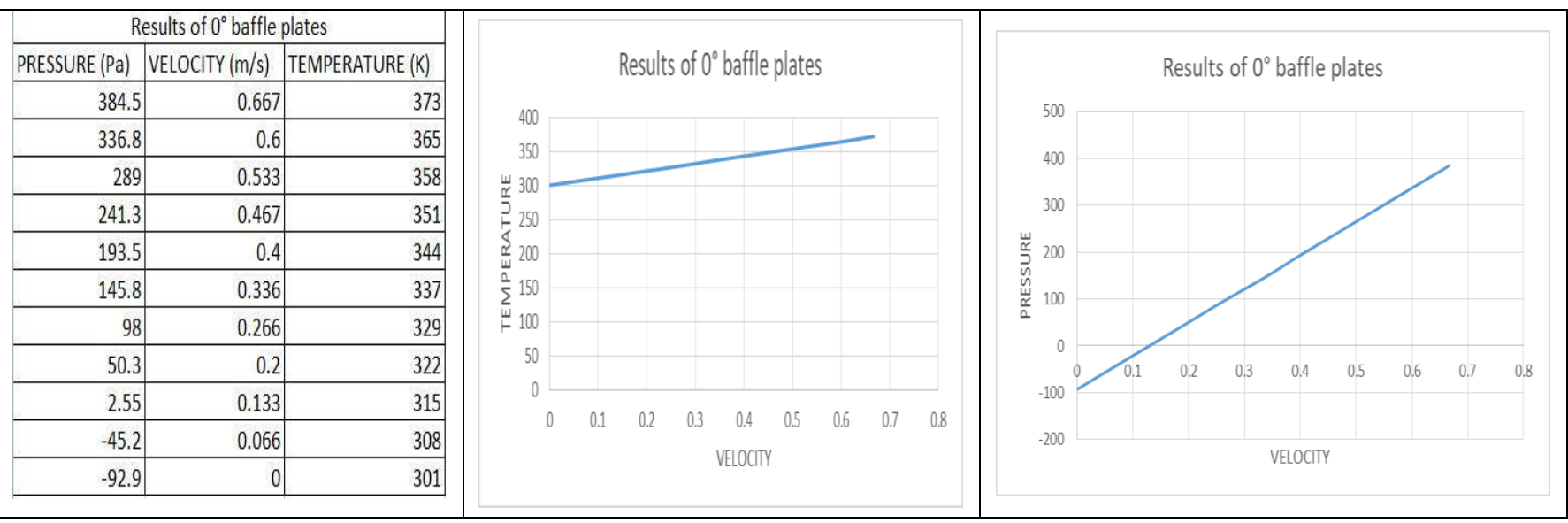

\subsection{Results of $15^{\circ}$ baffle plate}

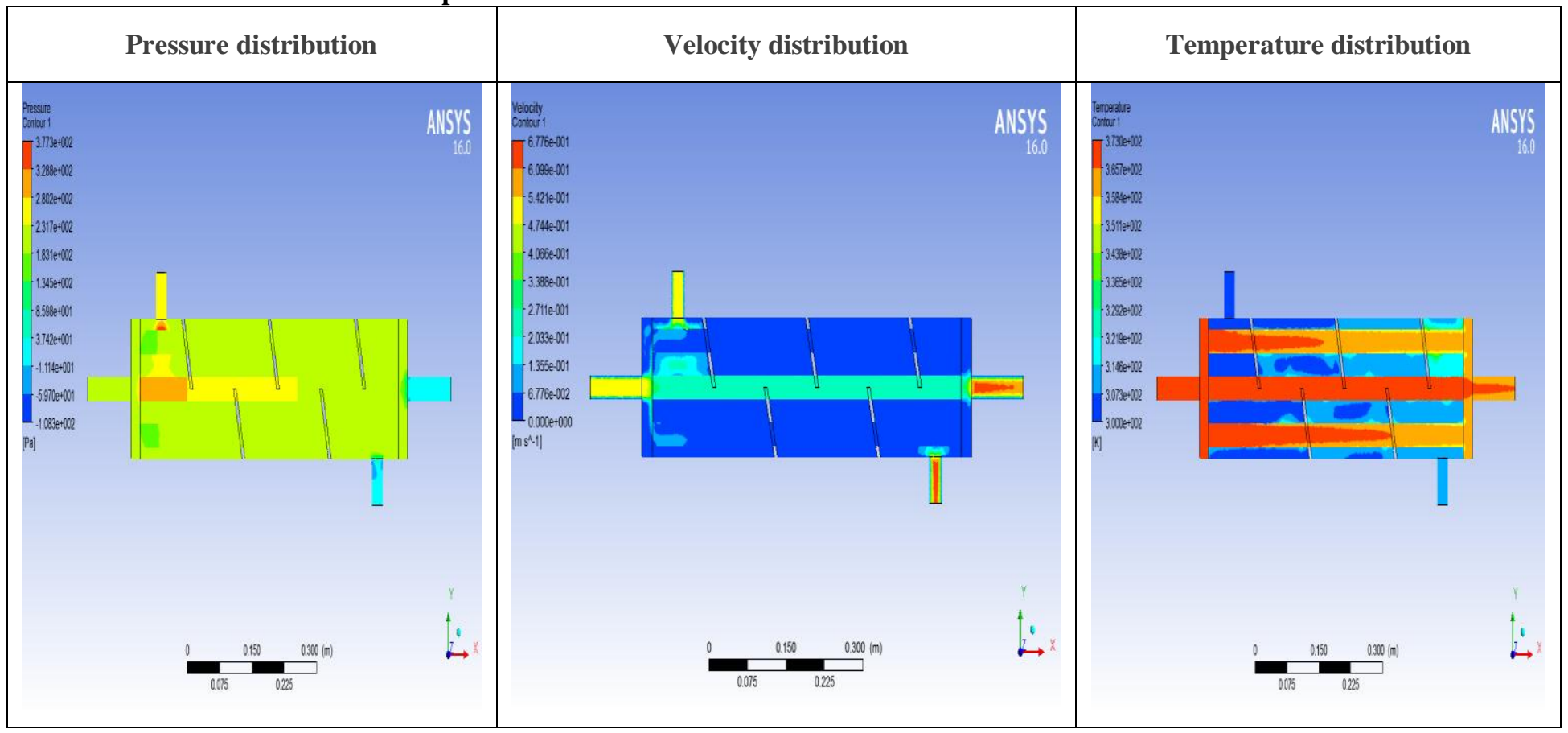




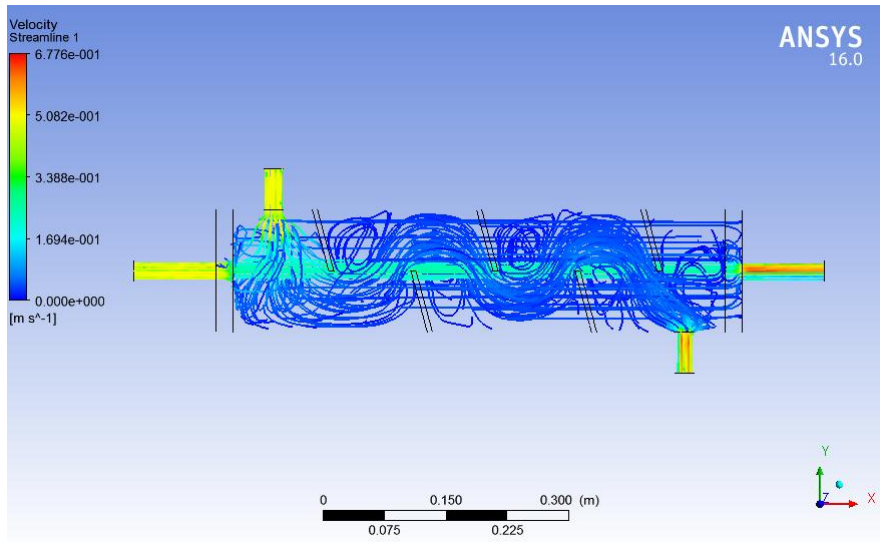

Flow Patterns On $15^{\circ}$ Baffle Plates

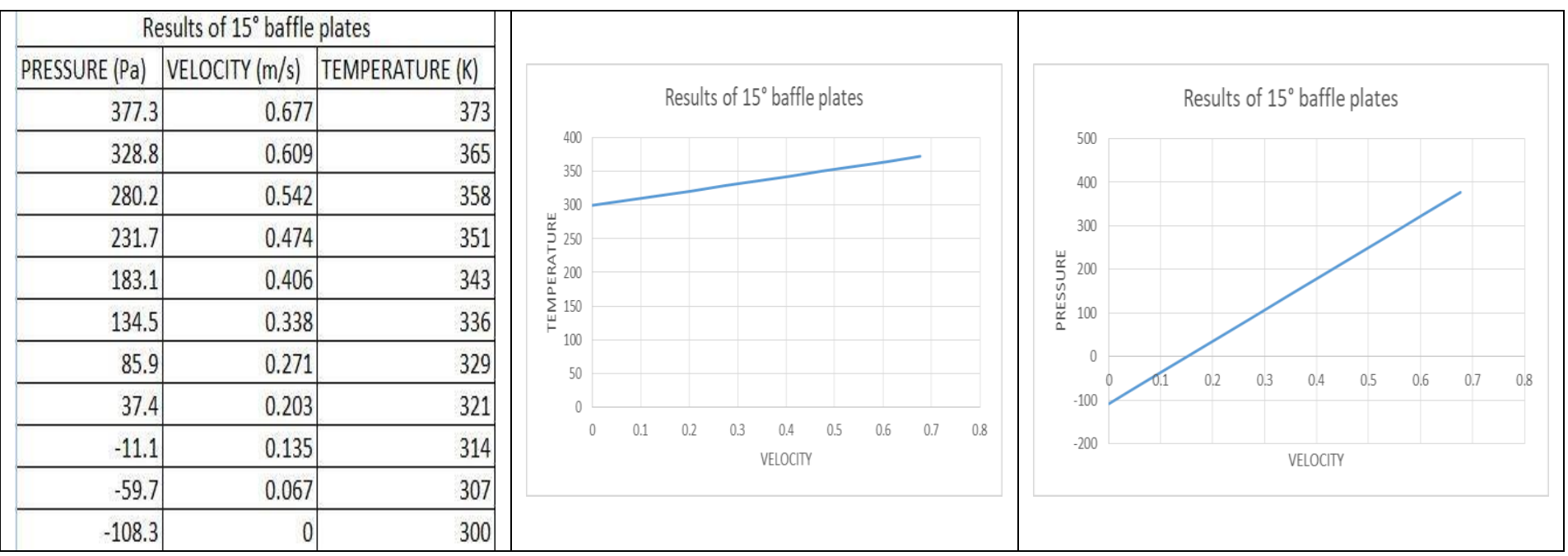

\subsection{Results of $25^{\circ}$ baffle plates}

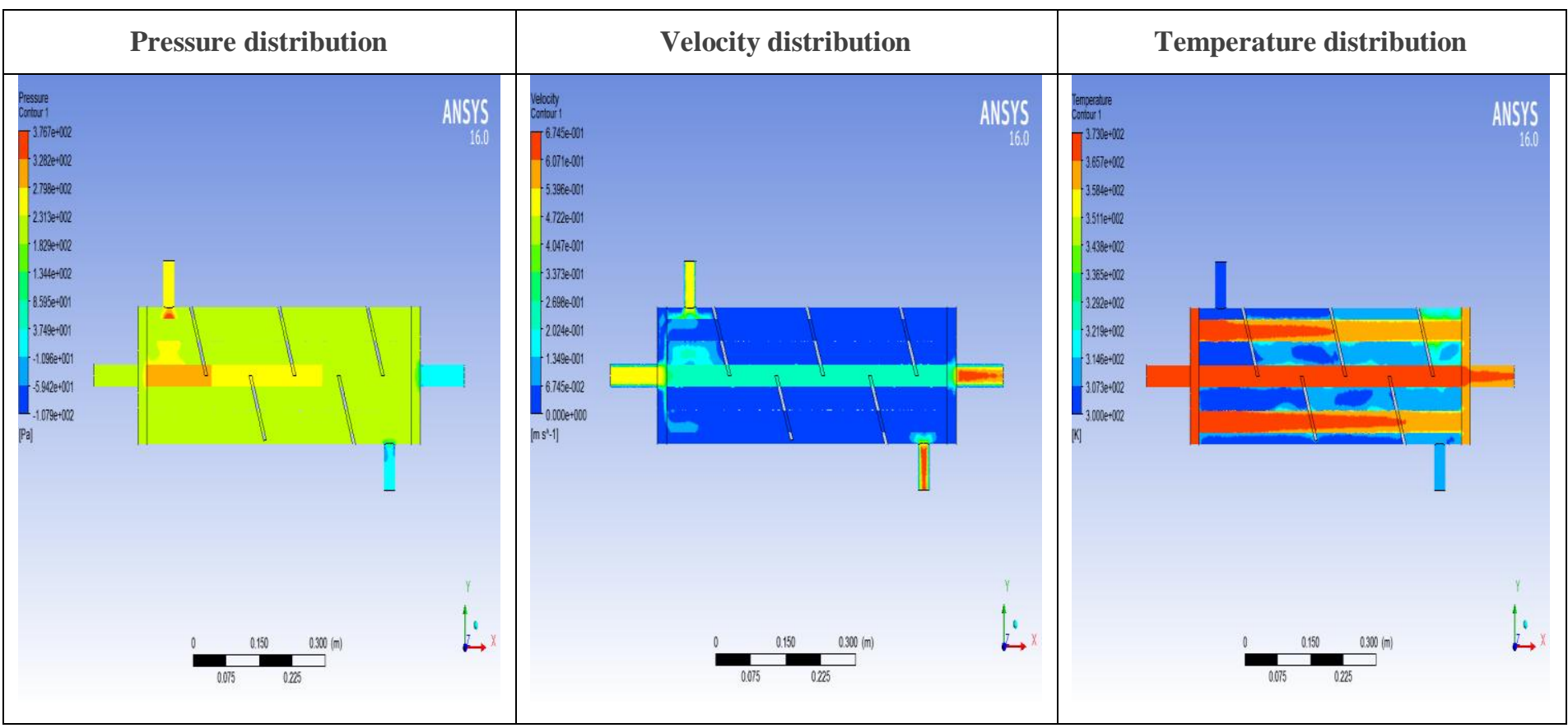




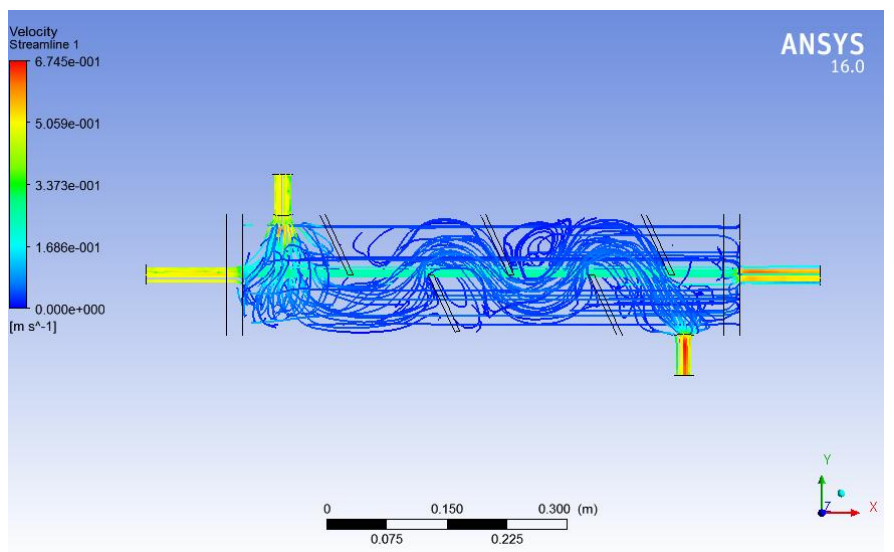

Flow Patterns On $25^{\circ}$ Baffle Plates

\begin{tabular}{r|r|r}
\hline \multicolumn{3}{|c}{ Results of $25^{\circ}$ baffle plates } \\
\hline PRESSURE (Pa) & VELOCITY $(\mathrm{m} / \mathrm{s})$ & TEMPERATURE $(\mathrm{K})$ \\
\hline 376.7 & 0.674 & 373 \\
\hline 328.2 & 0.607 & 365 \\
\hline 279.8 & 0.539 & 358 \\
\hline 231.3 & 0.472 & 351 \\
\hline 182.9 & 0.404 & 343 \\
\hline 134.4 & 0.373 & 336 \\
\hline 85.9 & 0.269 & 329 \\
\hline 37.4 & 0.202 & 321 \\
\hline-10.9 & 0.134 & 314 \\
\hline-59.4 & 0.0674 & 307 \\
\hline-107.9 & 0 & 300 \\
\hline
\end{tabular}

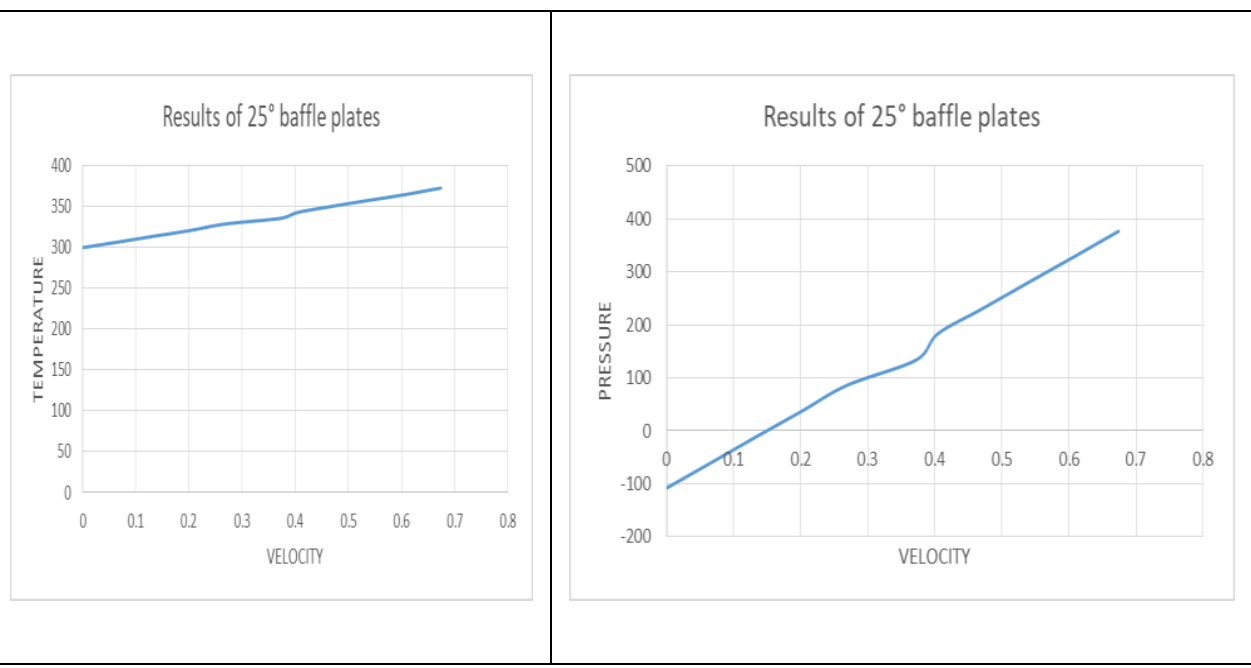

4.4 Results of $35^{\circ}$ baffle plates

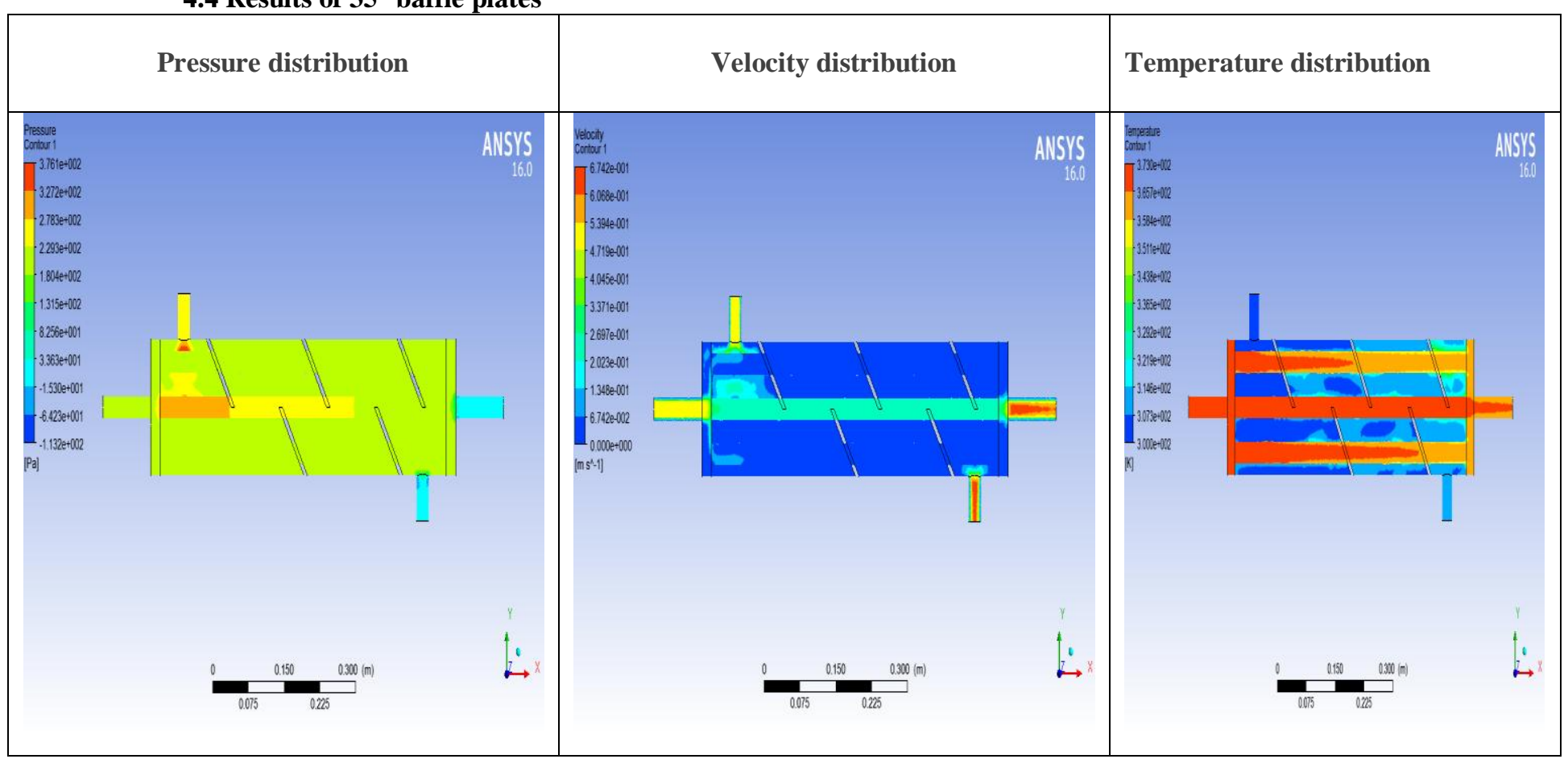




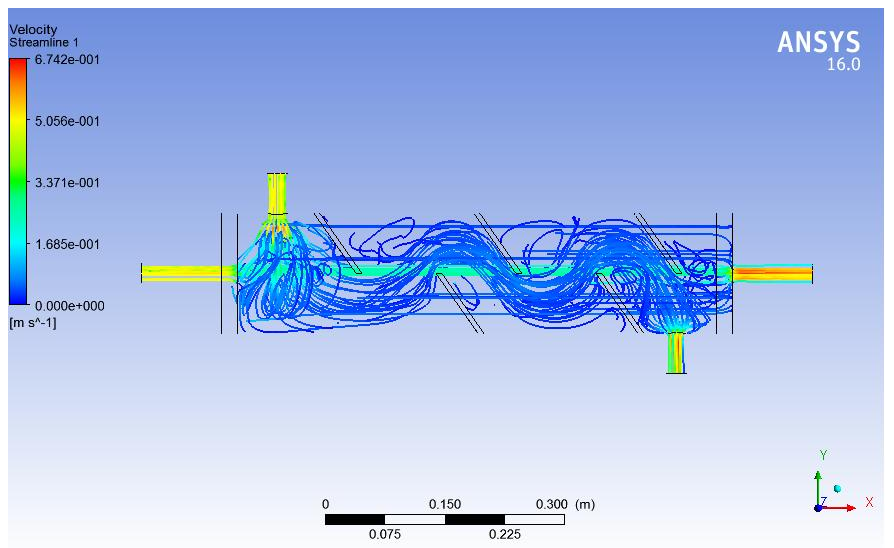

Flow Patterns On $35^{\circ}$ Baffle Plates

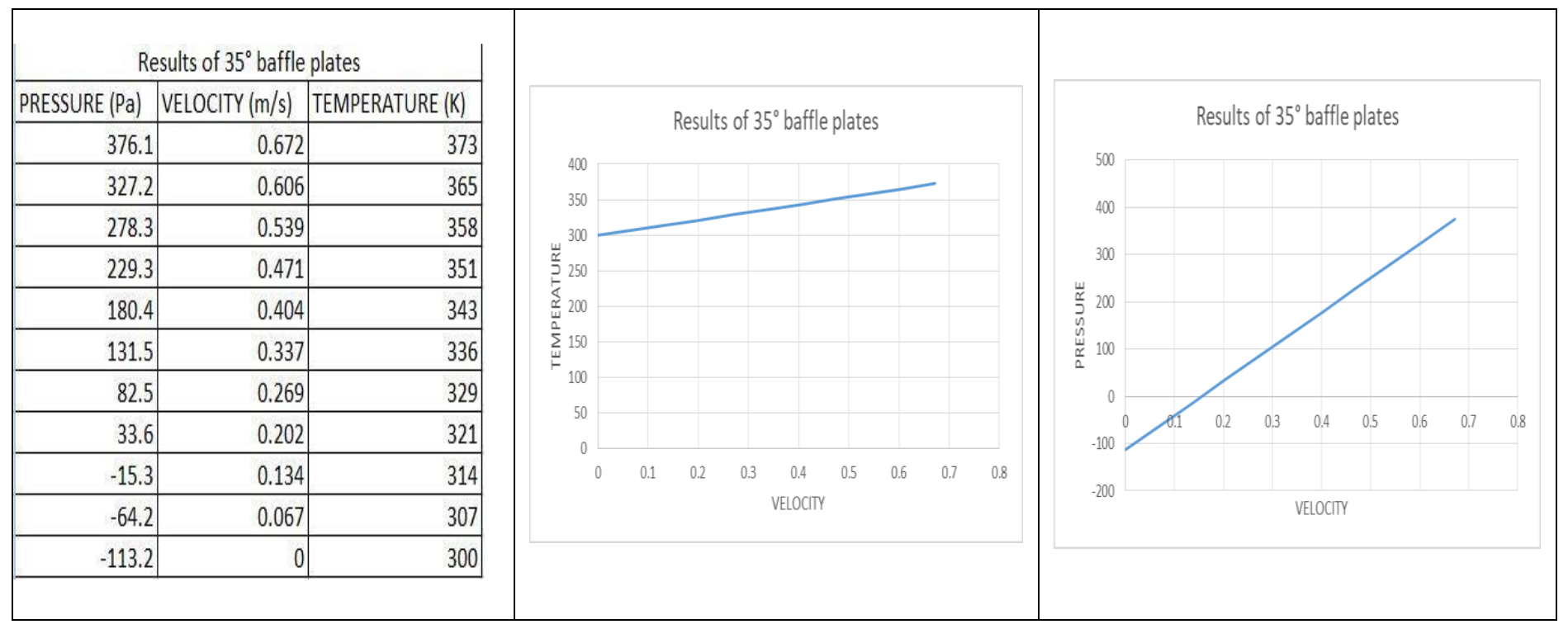

\subsection{TABULATED RESULTS}

\begin{tabular}{|c|c|c|c|c|}
\hline \multirow{2}{*}{ MODEL } & \multicolumn{2}{|c|}{ PRESSURE (PA) } & \multicolumn{2}{c|}{ VELOCITY (M/S) } \\
\cline { 2 - 5 } & MIN & MAX & MIN & MAX \\
\hline \multirow{2}{*}{$\mathbf{0}^{\circ}$} & -92.94 & $3.84 \mathrm{E}-2$ & 0 & $6.67 \mathrm{E}-1$ \\
\hline $\mathbf{1 5}^{\circ}$ & $-1.08 \mathrm{E} 2$ & $3.77 \mathrm{E} 2$ & 0 & $6.77 \mathrm{E}-1$ \\
\hline $\mathbf{2 5}^{\circ}$ & $-1.07 \mathrm{E} 2$ & $3.76 \mathrm{E} 2$ & 0 & $6.74 \mathrm{E}-1$ \\
\hline $\mathbf{3 5}^{\circ}$ & $-1.13 \mathrm{E} 2$ & $3.76 \mathrm{E} 2$ & 0 & $6.74 \mathrm{E}-1$ \\
\hline
\end{tabular}


Table 1: Baffle angle with Pressure and Velocity

\begin{tabular}{|c|c|c|c|c|}
\hline \multirow{2}{*}{ MODEL } & \multicolumn{2}{|c|}{ TEMPERATURE OF SHELL } & \multicolumn{2}{c|}{$\begin{array}{c}\text { TEMPERATURE OF } \\
\text { TUBE (K) }\end{array}$} \\
\cline { 2 - 5 } & INLET & OUTLET & INLET & OUTLET \\
\hline $0^{\circ}$ & 300 & 309.6 & 373 & 365.2 \\
\hline $\mathbf{1 5}^{\circ}$ & 300 & 308.8 & 373 & 364.6 \\
\hline $\mathbf{2 5}^{\circ}$ & 300 & 308.5 & 373 & 364 \\
\hline $\mathbf{3 5}^{\circ}$ & 300 & 308.5 & 373 & 364.1 \\
\hline
\end{tabular}

Table 2: Baffle angle with temperature of Shell and Tube

\section{CONCLUSION}

As the point of puzzles increments for same length of shell, at that point dispersing between the confuses are diminishing. Since the dispersing between the bewilder is less so the space of distribution is less and high disturbance is created. In high choppiness district, heat move rate is additionally high. Another focal point is that because of expansion in number of perplexes, liquid needs to cover more distance in the shell so the successful heat move region expands which is brings about high heat move rate. As the point of confounds builds, pressure drop in shell side increments. Since expanding in point of perplexes implies diminishing the space between astounds so the way for liquid stream gets limited. At the point when liquid goes through limited way, its pressing factor decline and motor energy increment. So pressure drop increments with expansion in number of puzzles. As the pressing factor drop increment siphoning power needed to keep up the stream is likewise increments. Pressing factor drop is an unfavourable wonder which ought to be thought about while planning the shell and cylinder heat exchanger.

\section{REFERENCES}

[1] Prof.SunilkumarShinde*,MustansirHatimPancha**, "Comparative Thermal Performance Analysis of Segmental Baffle Heat exchanger with Continuous Helical Baffle Heat Exchanger using Kern Method”,(Ijera),Vol.2., Issue 4, July-August 2012,Pp.22642271 .

[2] Qiuwang Wang et al,"Shell and Tube Heat Exchanger with Helical Baffles"Pub no.US 2011/0094720.Pub. Date- Apr.28, 2011..

[3] Bashir.I.Master et al,’Fouling mitigation using helixchanger heat exchangers.” Date:-2003.

[4] Mayankvishwakarma ," Performance Evaluation Of A helical Baffle Heat Exchanger” Date: June 2013.

[5] Ender Ozden "Shell side CFD analysis of a small shell-and-tube heat exchanger" Energy Conversion and Management 51 (2010) 1004-1014.

[6] Durgesh Bhatt "Shell and Tube Heat Exchanger Performance Analysis" International Journal of Science and Research (IJSR) ISSN (Online): 2319-7064 (2012).

[7] Srikanth GANNE "shell side numerical analysis of a shell and tube heat exchanger considering the effects of baffle inclination angle on fluid flow" Shell Side Numerical Analysis of a Shell and Tube Heat ... THERMAL SCIENCE: Year 2012, Vol. 16, No. 4, pp. 1165-1174.

[8] Nikhil P.Talwekar "Analysis and Experimentation of Shell and Tube Heat Exchanger with Different Orientation of Baffles" International Journal for Research in Applied Science \& Engineering Technology (IJRASET) Volume 4 Issue VI, June 2016 ISSN: 2321-9653. 